\title{
Gamma Equipment System Requirements by Application
}

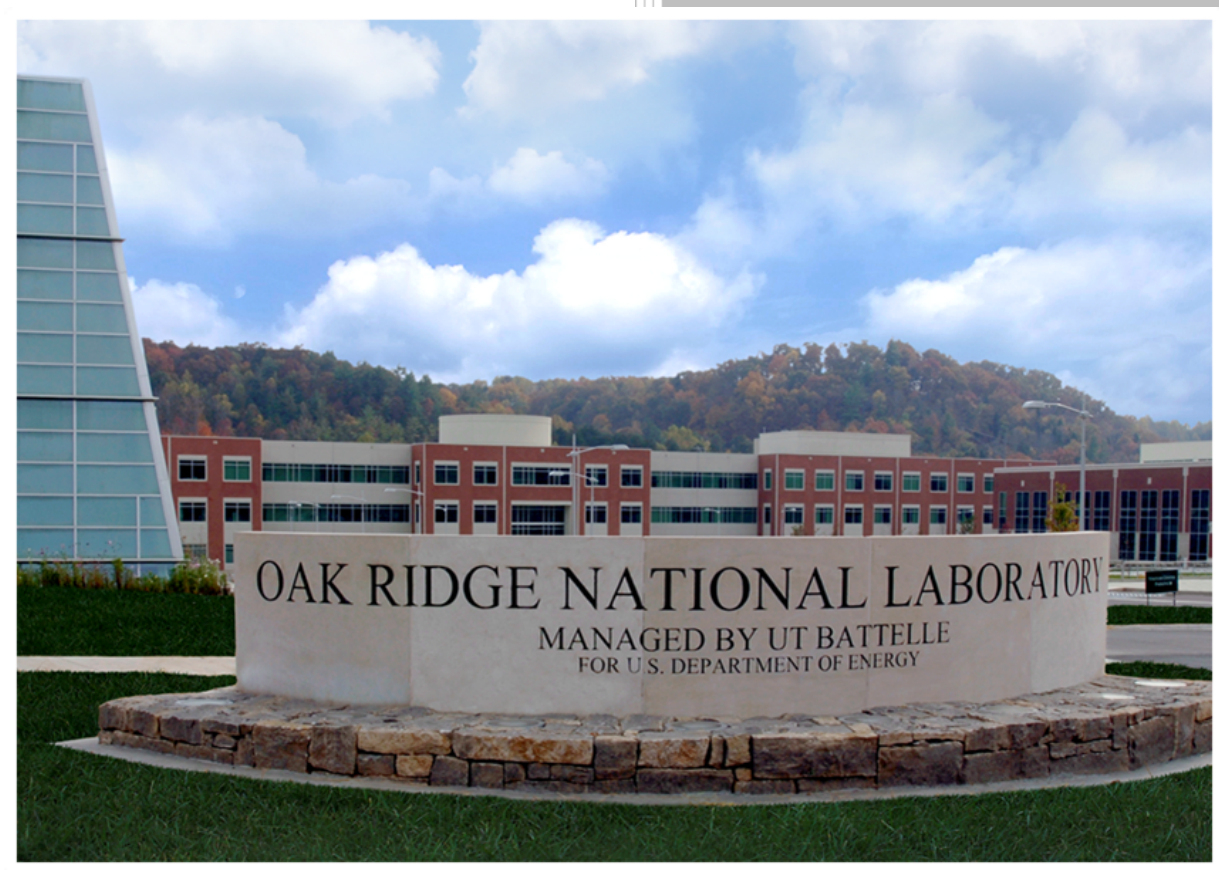
C. R. Brittain
R. D. McElroy Jr.
R. Venkataraman
M. P. Dion
S. Croft

March 2020 


\section{DOCUMENT AVAILABILITY}

Reports produced after January 1, 1996, are generally available free via US Department of Energy (DOE) SciTech Connect.

Website www.osti.gov

Reports produced before January 1, 1996, may be purchased by members of the public from the following source:

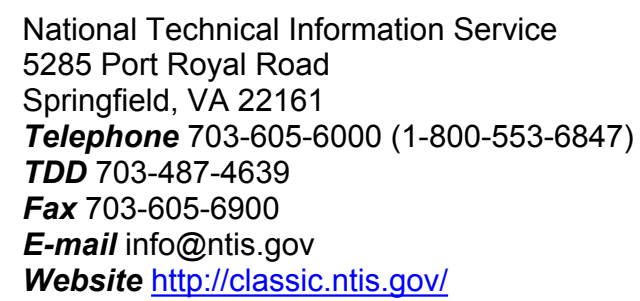

Reports are available to DOE employees, DOE contractors, Energy Technology Data Exchange representatives, and International Nuclear Information System representatives from the following source:

Office of Scientific and Technical Information

PO Box 62

Oak Ridge, TN 37831

Telephone 865-576-8401

Fax 865-576-5728

E-mail reports@osti.gov

Website http://www.osti.gov/contact.html

This report was prepared as an account of work sponsored by an agency of the United States Government. Neither the United States Government nor any agency thereof, nor any of their employees, makes any warranty, express or implied, or assumes any legal liability or responsibility for the accuracy, completeness, or usefulness of any information, apparatus, product, or process disclosed, or represents that its use would not infringe privately owned rights. Reference herein to any specific commercial product, process, or service by trade name, trademark, manufacturer, or otherwise, does not necessarily constitute or imply its endorsement, recommendation, or favoring by the United States Government or any agency thereof. The views and opinions of authors expressed herein do not necessarily state or reflect those of the United States Government or any agency thereof. 


\title{
Nuclear Nonproliferation Division
}

\section{GAMMA EQUIPMENT SYSTEM REQUIREMENTS BY APPLICATION}

\author{
C. R. Brittain
}

R. D. McElroy Jr.

R. Venkataraman

M. P. Dion

S. Croft

March 2020

Prepared by OAK RIDGE NATIONAL LABORATORY

Oak Ridge, TN 37831-6283

managed by

UT-BATTELLE, LLC

for the

US DEPARTMENT OF ENERGY

under contract DE-AC05-00OR22725 



\section{CONTENTS}

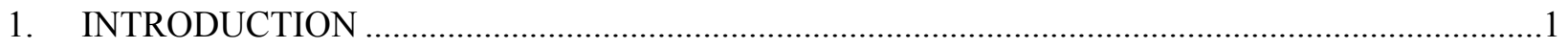

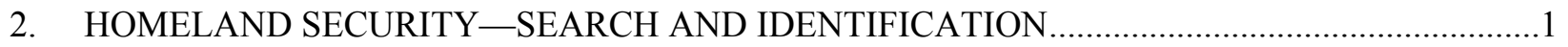

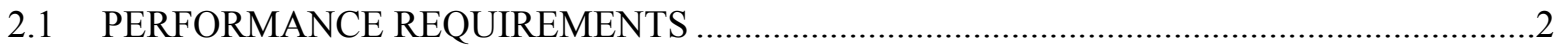

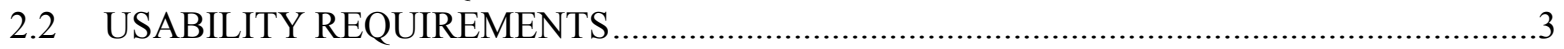

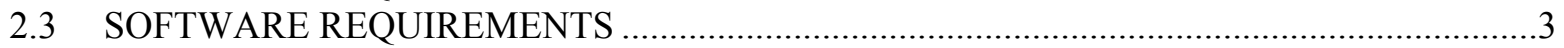

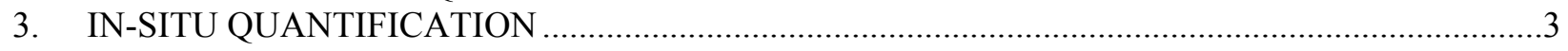

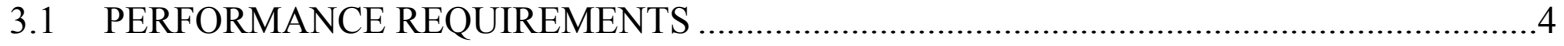

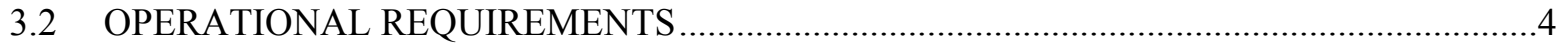

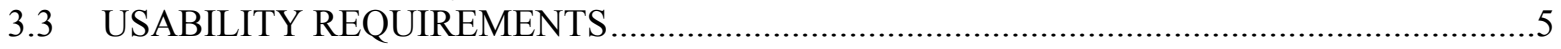

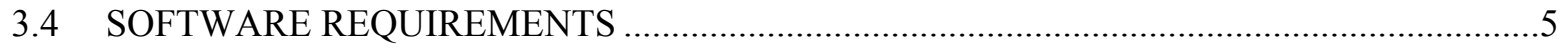

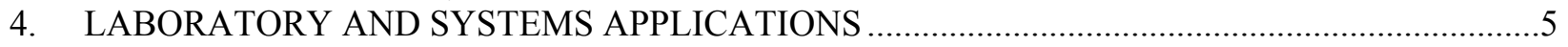

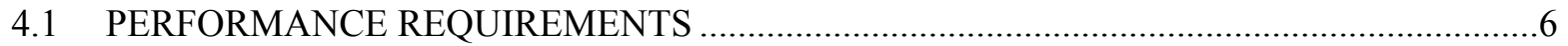

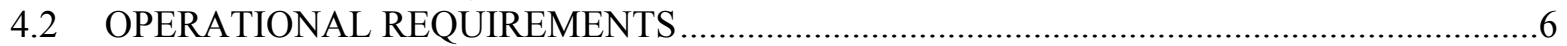

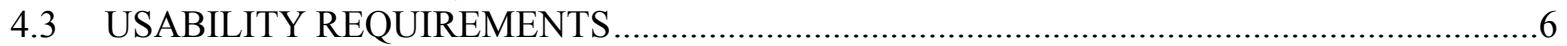

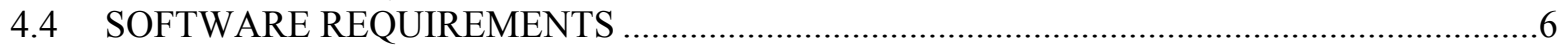

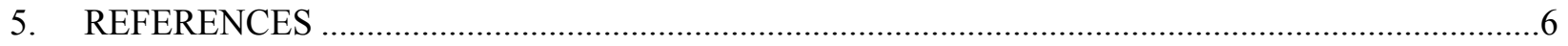




\section{INTRODUCTION}

This document outlines a set of requirements for gamma sensitive systems applied to three different applications: (1) homeland security (search and identification); (2) in-situ quantification; and (3) quantification in a material characterization laboratory. These three applications represent a range of activities that a country might use for locating, identifying, and quantifying radioactive material. These applications require increasing accuracy and system advancements, and skill levels.

This document considers systems with various detector types and are characterized by their energy resolution: (1) low resolution (e.g., $\mathrm{NaI}(\mathrm{Tl})$ scintillation) and (2) higher resolution (e.g., high-purity germanium [HPGe] solid state) systems. The higher resolution systems also include cadmium zinc telluride (CZT) and only mechanically cooled HPGe systems are considered. These detectors and their associated acquisition hardware and analysis software afford a broad range of capabilities with corresponding ranges of complexity, maintainability, and cost.

Ultimately, the equipment must meet the measurement goals of the application, and compliance with a given list of hardware specifications does not in itself guarantee meeting those goals. Examples of typical performance objectives for international safeguards applications are documented in International Target Values 2010 for Measurement Uncertainties in Safeguarding Nuclear Materials (IAEA, STR-368, November 2010). Selection of the detector type best suited to a specific application is often a compromise between "state of the art" or best available option and what is practical.

Owing to the usefulness, popularity, and availability of these radiometric systems, various guides and standards have been developed that should be met where applicable.

- ASTM Standard C1237-2005: Standard Guide to In-Plant Performance Evaluation of Hand-Held SNM Monitors

- ASTM C1726: Standard Guide for Use of Modeling for Passive Gamma Measurements

- ASTM C1030: Standard Test Method for Determination of Plutonium Isotopic Composition by Gamma-Ray Spectrometry

- ANSI N42.34-2015: American National Standard Performance Criteria for Handheld Instruments for the Detection and Identification of Radionuclides

- Technical Capability Standard for Handheld Instruments Used for the Detection and Identification of Radionuclides, Domestic Nuclear Detection Office (DNDO), Oct. 2011

\section{HOMELAND SECURITY - SEARCH AND IDENTIFICATION}

Detectors used for homeland security applications are intended for search missions and the identification of radionuclides and nuclear materials. These detectors are used for extended periods of time and deployed in various, sometimes isolated, applications. Because of this, they should be lightweight and easy to use. Ease of use could include an audible alarm to alert the operator of an identification. Additionally, the detectors should require minimal training. The radionuclide identification capability is very important in this scenario, but quantification of the amount of material is not (usually) performed.

A typical concept of operations for homeland security applications is to use many lower cost, lower resolution detectors to locate radioactive material and perhaps do an initial identification. These detectors would typically be scintillation-based systems, such as $\mathrm{NaI}(\mathrm{Tl})$. After the initial radionuclide identification is complete, a more expensive, higher resolution detector (i.e., HPGe) might be used to confirm the identification. This is especially important in scenarios of high environmental background or 
several radioactive sources that could cause identification issues in the low-resolution system(s). In this case, a higher resolution instrument could be used in these extreme (background) conditions.

These detector systems for search and identification are referred to as radioisotope identifiers (RIID) and some examples from various vendors are given below. The detectors are grouped by low- and highresolution. The newest models of handheld HPGe are still heavier than the NaI(Tl) but have seen significant weight reduction (e.g., the Fulcrum ${ }^{\mathrm{TM}}$ by PHDS).

Low Resolution Examples:

- FLIR Identifinder ${ }^{\circledR}$ - Lightweight, $\mathrm{NaI}(\mathrm{Tl})$ crystal, extensively used by law enforcement

- Thermo Scientific RIIDEye X-Lightweight, NaI(Tl) crystal

Higher Resolution Examples:

- ORTEC Detective X-HPGe crystal, mechanically cooled with high resolution with a total weight of about $15 \mathrm{lbs}$.

- PHDS Fulcrum ${ }^{\mathrm{TM}}$ - HPGe crystal, high resolution with a total weight of $8 \mathrm{lbs}$.

- H3D A100 - CZT based system with various sizes available. Total weight of $\sim 5 \mathrm{lbs}$.

- Kromek RayMon10 - Energy resolution of 2.0-2.5\% FWHM at $662 \mathrm{keV}$. Total weight of $\sim 2.5 \mathrm{lbs}$.

\subsection{PERFORMANCE REQUIREMENTS}

1. The system shall have the capability to perform gamma spectroscopy during a search and can assist in locating and identifying the source of radioactivity such as naturally occurring radioactive material, industrial isotopes (e.g., ${ }^{60} \mathrm{Co}$ ), medical isotopes (e.g., $\left.{ }^{99} \mathrm{Mo}\right)$, and special nuclear material (e.g., $\left.{ }^{239} \mathrm{Pu}\right)$.

2. The performance criteria for NaI(Tl),HPGe, and CZT based detectors are given in Tables 1a-c. These criteria were set by the International Working Group on Gamma Spectrometry Techniques.

Table 1a. Performance specification of NaI(Tl) system to search, locate, and identify.

\begin{tabular}{|c|c|}
\hline $\begin{array}{l}\text { Energy resolution (FWHM) } *{ }^{137} \mathrm{Cs} 662 \\
\mathrm{keV}\end{array}$ & $<7.5 \% \pm 0.5 \%$ \\
\hline
\end{tabular}

Table 1b. Performance specification of electrically cooled HPGe to identify isotopes that may be in the presence of high background.

\begin{tabular}{|l|l|}
\hline Resolution $\mathrm{Pu} 129 \mathrm{keV}$ & $<1,500 \mathrm{eV}$ \\
\hline Resolution Pu $662 \mathrm{keV}$ & $<1,900 \mathrm{eV}$ \\
\hline Resolution U $186 \mathrm{keV}$ & $<1,600 \mathrm{eV}$ \\
\hline Resolution U 1,001 keV & $<2,400 \mathrm{eV}$ \\
\hline FWTM*/FWHM & $\begin{array}{l}<1.95 \text { for one of the predominant single } \\
\text { peaks in the spectrum that is }>60 \mathrm{keV}\end{array}$ \\
\hline
\end{tabular}

*Full-width at tenth-maximum

Table 1c. Performance specification of CZT based systems to search, locate, and identify.

\begin{tabular}{|l|c|c|}
\hline & $500 \mathrm{~mm}^{3}$ & $4000 \mathrm{~mm}^{3}$ \\
\hline Resolution (FWHM) ${ }^{57} \mathrm{Co} 122 \mathrm{keV}$ & $<3.2 \%$ & $<7.2 \%$ \\
\hline Resolution (FWHM) ${ }^{137} \mathrm{Cs} 662 \mathrm{keV}$ & $<1.5 \%$ & $<3.1 \%$ \\
\hline
\end{tabular}




\begin{tabular}{|l|c|c|}
\hline FWTM/FWHM at $662 \mathrm{keV}$ & $<2.6$ & $<2.6$ \\
\hline
\end{tabular}

3. The system should have an optional neutron detection capability.

4. The system shall have an internal fixed library of radionuclides based on ANSI N42.34 and a radionuclide library that can be edited as required.

5. Data shall be displayed indicating the type of radioisotope, and for nuclear materials, a confidence indicator shall be provided on the detector itself (without a computer).

6. The system shall save gamma energy spectra and have the capability to off-load the spectra for further analysis.

7. The system should have a GPS receiver to record location data with spectra.

8. The system shall allow continuous dose rate monitoring either with the detector used for isotope identification or with a separate onboard detector (e.g., a Geiger-Müller tube).

\subsection{USABILITY REQUIREMENTS}

1. The system should weigh less than $7 \mathrm{~kg}(\approx 15 \mathrm{lb})$.

2. The system shall include battery support to run continuously for up to 8 hours. Additional batteries and chargers shall be provided such that continuous battery operation can be maintained while spent batteries are being recharged.

3. The system shall be complete with all necessary cables, connectors, adapters, carrying case, and user manuals for complete operation.

\subsection{SOFTWARE REQUIREMENTS}

1. Gain stabilization shall be automatically performed to account for temperature or other shifts in the detector response function.

2. The system shall be self-contained with everything needed for search and identification of nuclear materials (no external computer required).

3. Gain stabilization shall be automatically performed to account for temperature or other shifts in the detector response function.

4. Software shall be available for analyses to further analyze downloaded gamma-ray energy spectra.

\section{IN-SITU QUANTIFICATION}

The objective for systems used for in-situ quantification applications is to quantify radioactive material. To do this, high-resolution detectors are required. The detectors generally have mechanically cooled HPGe crystals, however room temperature semi-conductors could also be considered (i.e., CZT)

The overall system weight is less of an issue. Typically, to make accurate measurements, significant shielding is required. Also, line (AC) power would generally be available, although battery power would 
also be desirable. The system will need to be transportable for short distances, and it should be liquid nitrogen-free, with electrical or mechanical cooling of the detector.

Since the objective is quantification of radioactive material, the detection system must support efficiency calibration for a wide variety of sample shapes and sizes. The efficiency calibration methods supported must include traditional gamma ray standard source-based methods as well as those based on mathematical efficiency calibration methods; (e.g., In Situ Object Calibration Software [ISOCS] ${ }^{1}$, ISOTOPIC $^{2}$, Monte Carlo N-Particle $[\mathrm{MCNP}]^{3}$ code). Table 1 in the ASTM Standard Guide C1726 provides detailed information about the applicability of various mathematical modeling methods to different measurement scenarios.

Examples of detectors that are in this list include:

- ORTEC Micro Detective - $50 \mathrm{~mm}$ diameter by $33 \mathrm{~mm}$ coaxial HPGe crystal, $\sim 2.1 \mathrm{keV}$ at $1332 \mathrm{keV}$ energy resolution

- ORTEC Detective $200-85 \mathrm{~mm}$ diameter by $30 \mathrm{~mm}$ coaxial HPGe crystal, $\sim 2.1 \mathrm{keV}$ at $1332 \mathrm{keV}$ energy resolution

- PHDS Fulcrum ${ }^{\mathrm{TM}}$ - $60 \mathrm{~mm}$ diameter $25 \mathrm{~mm}$ thick semi-hemispherical HPGe crystal, $2.0 \mathrm{keV}$ at $1332 \mathrm{keV}$ energy resolution, with a total weight of $8 \mathrm{lbs}$.

- Mirion Aegis ${ }^{\mathrm{TM}}$ - Choice of three different HPGe crystals and a remote detection chamber (RDC) option combining for six different configurations, laboratory-grade energy resolution,

\subsection{PERFORMANCE REQUIREMENTS}

1. The system shall have the capability to perform gamma spectroscopy to quantify sources of special nuclear material.

2. The system shall operate in the energy range of $40 \mathrm{keV}$ to $3 \mathrm{MeV}$ with an FWHM of $\leq 1.4 \mathrm{keV}$ at $122 \mathrm{keV}$ and $\leq 2.3 \mathrm{keV}$ at $1,332 \mathrm{keV}$.

3. The system shall have an internal fixed library of radionuclides based on ANSI N42.34 and a radionuclide library that can be edited is required.

4. Data shall be displayed indicating the type of radioisotope, and for nuclear materials, a confidence indicator shall be provided.

5. The system shall save gamma energy spectra and have the capability to off-load the spectra for further analysis.

6. Software shall be provided for gamma-ray energy analyses to further identify isotopes.

7. The system shall continuously monitor the environmental dose rate either with the detector used for isotope identification or with a separate onboard detector (e.g., a Geiger-Müller tube).

\subsection{OPERATIONAL REQUIREMENTS}

1. The system shall be liquid nitrogen-free, with electrical or mechanical cooling of the detector.

2. The system cool-down time should be $<6$ hours. 


\subsection{USABILITY REQUIREMENTS}

1. The system shall weigh less than $23 \mathrm{~kg}(\approx 50 \mathrm{lb})$.

2. The system shall include battery support to run continuously for up to 4 hours. Additional batteries and chargers shall be provided such that continuous battery operation can be maintained while spent batteries are being recharged.

3. The system shall be complete with all necessary cables, connectors, adapters, carrying case, and user manuals for complete operation.

\subsection{SOFTWARE REQUIREMENTS}

1. Gain stabilization shall be automatically performed to account for temperature or other shifts in the detector response function.

2. The system shall include software that can acquire and analyze gamma-ray spectra, perform nuclide identification, and determine and report the activities and/or mass of various isotopes in the sample.

3. A key component of gamma spectrometry analysis is efficiency calibration of the detector for the source geometry. The software shall support a traditional gamma ray standard source-based efficiency calibration. The software must also support the use of mathematical efficiency calibration methods such as ISOCS, ISOTOPIC, and MCNP.

\section{LABORATORY AND SYSTEMS APPLICATIONS}

The objective for systems used in a laboratory setting is to accurately and precisely determine the isotopic makeup and quantity of material and/or samples for nondestructive assay applications. To accomplish this, a system with high energy resolution, shielding, and adequate software to characterize material is required. Systems for this application should be HPGe detectors.

The performance requirements for a laboratory system will be the most stringent of all applications. Accuracy is crucial to the measurements made in this environment. High-energy resolution is required to accurately identify isotopics of special nuclear material, and spectra that have complicated background and source combinations.

The usability requirements for a laboratory system are generally less stringent than for other applications. The equipment will be used in a laboratory setting where it will not need to be hand carried, can easily be connected to power, and can be kept cool.

The detection system must support efficiency calibration for a wide variety of sample shapes and sizes. The efficiency calibration methods supported must include traditional gamma ray standard source-based methods as well as those based on mathematical efficiency calibration methods (e.g., ISOCS, ISOTOPIC, and MCNP).

The following examples of systems used for this application are:

- Mirion Aegis ${ }^{\mathrm{TM}}$ - Choice of three different HPGe crystals and also a remote detection chamber (RDC) option combining for six different configurations, laboratory-grade energy resolution,

- ORTEC Detective 200 - $85 \mathrm{~mm}$ diameter by $30 \mathrm{~mm}$ coaxial HPGe crystal. 


\subsection{PERFORMANCE REQUIREMENTS}

1. The system shall operate in the energy range of $40 \mathrm{keV}$ to $3 \mathrm{MeV}$ with a FWHM of $\leq 1.0 \mathrm{keV}$ at $122 \mathrm{keV}$ and $\leq 2.1 \mathrm{keV}$ at $1,332 \mathrm{keV}$.

2. The system shall have a multichannel analyzer with a minimum of 8,192 channels.

3. The system shall be able to distinguish between depleted uranium, natural uranium, low-enriched uranium, highly enriched uranium, weapons-grade plutonium, and reactor-grade plutonium.

4. The system shall have an internal fixed library of radionuclides based on ANSI N42.34, and a radionuclide library that can be edited as required.

\subsection{OPERATIONAL REQUIREMENTS}

1. The system cool-down time should be $<12$ hours.

\subsection{USABILITY REQUIREMENTS}

1. The system shall have available shielding to prevent environmental radiation from obscuring the measurement.

2. The system shall also have the capability to operate with a 100-240 VAC power source.

3. The system shall include a laptop to identify isotopes in a sample and perform efficiency calibration with software.

4. The system shall be complete with all necessary cables, connectors, adapters, and user manuals for complete operation.

\subsection{SOFTWARE REQUIREMENTS}

1. The system shall include software package that can acquire and analyze gamma-ray spectra, perform nuclide identification, determine and report the activities and/or mass of the various isotopes identified in the sample.

2. The system shall include software for analyzing material isotopics. Some of the commonly used isotopic analysis software are Multi-Group Analysis for Uranium (MGAU), ${ }^{4}$ Multi-Group Analysis (MGA), ${ }^{5}$ MGA,$++{ }^{6}$ Fixed-Energy Response Function Analysis with Multiple Efficiencies (FRAM), ${ }^{7}$ and Actinides Gamma Isotopics (IGA). ${ }^{8}$

3. The software shall support traditional gamma-ray standard source-based efficiency calibration. The software must also support the use of mathematical efficiency calibration methods such as ISOCS, ISOTOPIC, and MCNP.

\section{REFERENCES}

1. R. Venkataraman, F. Bronson, V. Atrashkevich, M. Field, and B. M. Young, "Improved Detector Response Characterization Method in ISOCS and LabSOCS," J. Rad. Nucl. Chem., Vol. 264, No. 1, pp. 213-219 (2005). 
2. Hagenauer, R. C., et al., "Evaluation of Program Isotopic to Nondestructively Quantify Uranium and Plutonium Samples at the Joint Research Center in Ispra, Italy," Proceedings

from the 25th Annual Meeting Symposium on Safeguards and Nuclear Materials Management, May 2003.

3. Monte Carlo N-Particle ${ }^{\circledR}$ Transport Code System Version 6.2, Los Alamos National Laboratory, March 2018.

4. A. Bosko, S. Philips, T. Gerent, R. Gunnink, "MGAU4.2: The Latest Evolution in the MultiGroup Analysis Code for Uranium," Proceedings of 52nd Annual Symposium of the Institute of Nuclear Material Management, 2011.

5. MGA,: https://mirion.s3.amazonaws.com/cms4_mirion/files/pdf/specsheets/c38690 mga super spec 1.pdf?1557863532

6. MGA++ V1.06 Safeguards Software, http://www.ortec.com/media/ametekortec/brochures.

7. T. Sampson, T. Kelley, and D. T. Vo, Application Guide to Using the Gamma Ray Isotopic Analysis Using the FRAM Software, LA-14018, Los Alamos National Laboratory September 2003.

8. Actinides Gamma Isotopics (IGA),https://hal-cea.archives-ouvertes.fr/cea-01682396 